\title{
Economic Analysis of Food Security in Peshawar, Pakistan
}

\author{
Sundus Hussain ${ }^{1}$, Hina Hussain ${ }^{2}$, Muhammad Nisar ${ }^{3}$ Seema Zubair*4 \\ 1. Department of Statistics, Shaheed Benazir Bhutto Women University, Peshawar, Pakistan. \\ 2. Department of Economics, Faculty of Social Sciences, University of Peshawar, Pakistan. \\ 3. Department of Sociology, Bacha Khan University, Charsadda, Pakistan. \\ 4. Department of Statistics, Carleton University, Ottawa, Ontario, Canada.
}

\begin{abstract}
To investigate and explore the condition of food security in District Peshawar, Khyber Pakhtunkhwa, 300 citizens were interviewed. The econometric tool of Pearson's Product Moment Correlation Coefficient analysis was used and applied for analysis and estimating the data collected. It was concluded from the analysis that food security shows strong and negative relationships with the rise in population growth, rise in biofuel production, rise in poverty and rise in social unrest. Food insecurity is a major issue in KP that must be solved as soon as possible. Poor people are suffering the most and are unable to buy basic food items due to high prices. Food demand is increasing day by day because of larger population, thus resulting in an inflation of food prices. Effective measures are needed to control and reduce the growing rate of population. To eradicate food insecurity, agricultural institutions must be intensified and strengthened, infrastructure and storage facilities must be enhanced and developed, investment and latest machinery \& technology are required to be inserted into an inactive agricultural sector.
\end{abstract}

Keywords: Biofuel, Food Insecurity, Population Growth, Social Unrest, Poverty.

\section{Introduction}

One of the daunting challenges in Pakistan is food insecurity. According to world food program 2017 about $60 \%$ of Pakistan's population is food insecure, whereas $56 \%$ is insecure only in the province of KP (Gulab et al., 2018). In Pakistan, although there is the availability of food, but still most of the people are going through food scarcity, including famine because of the inadequacy to access food. This condition is mainly due to poverty, because poor people lack the purchasing power to buy the sufficient quantity and quality of food (Kugelman, 2010).

The issue of food security for vulnerable families is closely related to migration because these households have limited employment opportunities, and when combined with limited or no agricultural land, they are more prone to migration (Ahmad \& Afzal, 2020). Food safety problems are becoming increasingly common in the modern world because of the adverse effects of floods that often occur as a result of climate change (Week \& Wizor 2020). Inadequate food availability, unavailability and food purchasing power are all linked to food insecurity (Abid et al. 2016; Ahmad et al. 2020). 
Food insecurity is an effect of poverty and inadequate availability of food. In Pakistan during 1987-2007, almost one-third of families living down the food deprivation line and were unable to confront dietary requisites. In rural regions the degree of food insecurity is greater (35 percent), than in urban regions $26 \%$ (Arif \& Khalid, 2007).

Apart from the benefits of global food production, in a few decades, even now, some 800 million people are estimated to be malnourished worldwide (Nyarko \& Kassai 2017). During global crisis of food 2007-08, Pakistan had also suffered. There was a scarcity of wheat and people faced higher prices of food items; food inflation pointed to 30 percent in 2007. Millions of people were pushed into poverty and starvation because of this crisis, so poverty is an increasing issue in Pakistan. Although Pakistan is already facing war against terrorism, yet it becomes very difficult to manage both borders (Malik et al., 2015).

Excessive variations in rainfall, drought, temperature and flooding due to environmental expansion have exacerbated the problem of food security at the family and national level, especially in the riverine regions of developing nations (Př́vara and Př́varová 2019; Alam et al. 2020).

The World Food Program revealed that in Pakistan, almost 50 percent of people consume deficient quantity than the minimal quantity necessary for an average human need. In Pakistan the regions which are immensely affected by the food insecurity problem are: Balochistan, the Federally Administered Tribal Areas (FATA), and KP. Farming households are facing minimum food scarcity in the northern Punjab (Toor, 2010).

The rises in food prices, alarming inflation and sluggish incomes have destroyed purchasing power and further crowded access to food for an increasing sector of the population. Due to the world economic deterioration, the downfall in manufacturing output and exports has caused serious job losses and many families were out of income (Altaf, 2009). Unemployment and the considerable income loss have severe intimations for the security of food. Such disturbing situation is the reason behind economic instability and food insecurity in the area (Bengali \& Jury, 2010).

During the year 1973, 1988, 1992 and 2010 Pakistan had experienced severe droughts and floods. The government is following programs of support acquisition prices, distribution and storage at great cost, simply to accommodate the deficiencies in rural/urban regions and rescue individuals from high prices of food (Ahmad \& Farooq, 2010).

In KP, during 2009, almost 24 districts are lack in production of wheat. The KP is more exposed to food insecurity as wheat is supplied to Afghanistan and Federally Administrated Tribal Area (FATA). The KP is facing cereal deficiency due to insignificant landholding, shortage of cultivated land and larger population mass. In terms of production, the cereal lacking districts are Peshawar, Kohat, Karak, Lakki Marwat, Tank, Bannu, Abbottabad, Nowshera, Lower Dir, Hangu and Upper Dir. From 24 districts, 23 are having problems in facing lack of crop-based food, only D. I. Khan successes to manage its own necessity. Peshawar, Kohistan, Karak, Abbottabad, Lakki Marwat, Hangu, Bannu, Lower Dir, Shangla, Upper Dir, Chitral, Nowshera and Battagram are the worst crop-based food shortage districts. Most of the districts (83 percent) are facing tremendously small access to food items. In KP, food security situation is getting worse day by day and it is harshly affecting people (Arshad \& Shafqat 2012). 
The KP economy has already been invaded and assaulted because of severe food insecurity. It has accomplished the critical and crucial malnourishment and persistent hunger and famine. A high food price has generated extensive and prevailing destruction and chaos in the form of starvation, famine, social, political and economic instability and insecurity (Gulab et al., 2018). The availability of food for poor and low-income households is adversely affected by high food prices due to demand and the gap in crop production which has been reduced due to flood hazards and increased food demand due to population growth (Abbas et al. 2017; Ahmad et al. 2019).

The province of KP is facing severe problem of food insecurity and it is importing subsidized food from other provinces because they are not producing enough quantity to fulfill the demand. Therefor it is important to adopt advance technology and tools of agriculture to increase the production and fill the gap amongst supply of food and its demand (Zhou et al., 2019). Whereas the agricultural sector alone may not achieve food security results unless a multi-sectorial approach is implemented to address hunger and malnutrition (Farrukh et al., 2020).

The malnourished, famine and hunger affected population is incapable to grant and devote to a strong, healthy and flourishing functioning and operating civilized authority for the KP's prosperity and comfort. Hence, there is a need to present and serve each and every feasible and attainable aim and measure to eradicate this crisis and guarantee that each and every individual is well-fed and nourished and provide economic strength to the KP.

This study will help in exploring and analyzing the condition of food security in the KP, as food insecurity is a very important issue and needs to be resolved as soon as possible. There are many people dying in the KP today because of the lack of food for them to eat. Efficient advanced actions and efforts are needed simply to end food insecurity, and people of KP can live a healthy life. Thus, governmental and non-governmental organizations will also get benefit from this study, involved in promoting KP's food security.

Purpose of this paper is to explore the relationship between food security \& rise in population growth, rise in biofuel production, rise in poverty and rise in social unrest. District Peshawar is considered in this study about food security condition in KP. Sample size of 300 individuals (both gender) selected randomly in which individuals of all classes i.e., upper, middle and lower are taken. The study is based on primary source of data. For collecting primary data, Direct Personal Interviews method is used. For the analysis of relationship between variables an econometric tool of Pearson Product- Moment Correlation Coefficient is used in the study. It is revealed from the analysis that food security has a strong negative relationship with increase in population growth, upswing in production of biofuel, rapid increase of poverty and increase in social unrest.

Some recommendations are suggested to control the problem of food insecurity that it must be affirmed on a regular ground, partly after every one or two years. Efforts should be made to compose and prepare maintainable, feasible and viable plans and strategies for the preservation and adequate usage of water. There is a need for a continuous investment in agricultural sector to generate advanced varieties that are suitable to the changing climate. For a better availability of food, appropriate measures should be taken i.e., cultivating and advancing our own offshore, extending and enlarging area, boosting and promoting farm productivity, decrease post- harvest 
damages, limiting and confined exports, expanding imports. For a valuable and better food access, strengthen and sustain free trade, focus on feeding plans, advance organizations and strategies, manage and operate prices, provision of money transmission, allowances etc., and provision of food aid. For an advance and improve utilization of food, cultivate and prosper new products, enhance and upgrade food safety, instruct, teach and train consumers and food service operators, advance and enhance diet and nourishment, make strong and secure the existing products.

\section{Research Methodology}

\subsection{Research Area}

District Peshawar is taken in to consideration for the collection of facts about food security condition in KP. Small size of population is considered for this study because of the time and financial limit. Peshawar is a rapidly growing city with a population of $1,970,042$ according to 2017 census that was 982,816 according to 1998 census and 566,248 in 1981.

\subsection{Data Description and Analytical Technique}

300 citizens (both gender) are selected randomly in Peshawar. All class of citizens upper, middle and lower are taken. The study is based on primary source of data. For collecting primary data, Direct Personal Interviews method is used. Twenty five (25) questions are structured and weighted as YES or NO; with the aim of investigating is there any relationship between food security and rise in population growth, rise in biofuel production, rise in poverty and rise in social unrest or not. The responses of the respondents are analyzed and the Econometric tool of Pearson Product- Moment Correlation Coefficient is used for analyzing the relationship between the variables. The sample size is systematically selected by using the formula:

$$
\mathrm{n}=\mathrm{Ns^{2 }}
$$

Where,

$\mathrm{n}=$ Sample Size

$\mathrm{N}=$ Population Size

$$
s^{2}=\text { Sample Variance }=\frac{\sum(Y-\hat{Y})^{2}}{\mathrm{n}-1}
$$

$\mathrm{D}=B^{2} / 4$

$\mathrm{B}=$ Bound on the error of estimation

\section{Data Presentation and Analysis}

\subsection{Analysis and Interpretation}

Out of 300 sample size, 200 males and 100 females were interviewed. 281 claimed that food security does not exist in the KP. Thus, KP is going through severe food insecurity. 284 respondents out of 300 are of the opinion that rapid population growth affects food production. 284 argued that pressure of population growth and a retreating resource in the coming century 
will threaten security of food. 285 claimed that population size should be reduced to attain sustainable food security. 282 are of the opinion that increase in population is a determinant of food crisis. 280 out of 300 respondents argued that increase in the price of crude oil is responsible for increase in prices of food. 275 out of 300 respondents are of the opinion that it is not possible to assure food security alongside biofuel production. 273 out of 300 respondents are of the opinion that biofuels production rapid increase has severe effects on the obtainability of sufficient food supplies for individuals, by diverting water, grounds, and other resources away from feed crops and food. 280 out of 300 respondents having the opinion that more grains are purchased by deprived people e.g. wheat, and exposed more to changes of grain price. 278 respondents out of 300 having the opinion that a higher portion of income are spend on food by deprived people, so increasing prices of food have more effect on them. 274 respondents out of 300 claimed that they and their family could not afford to eat balanced meals. 260 respondents out of 300 are of the opinion that high food prices are causally associated with social unrest.

259 respondents out of 300 claimed that $\mathrm{KP}$ is most at risk of social unrest from food shortages and high food prices. 262 respondents out of 300 are of the opinion that crime rates have been increased due to food insecurity. 260 claimed that suicide rates have been increased due to food insecurity. 263 claimed that terrorism rates have been increased due to food insecurity.

\subsection{Statistical Analysis}

The figure-1 shows strong and negative relationship between Food security \& rise in Population growth.

Figure 1: Relationship between Food Security \& Rise in Population Growth

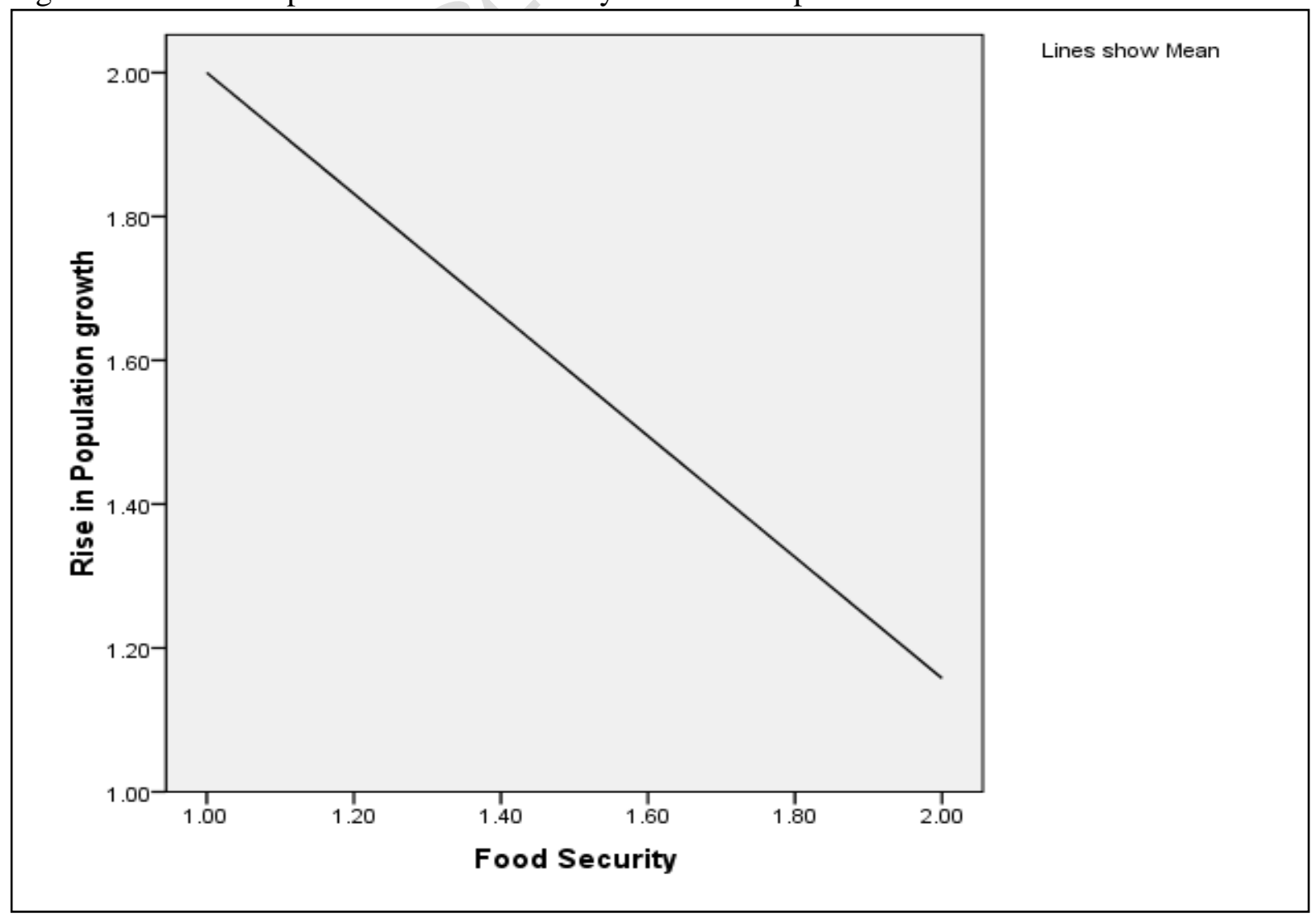


The Econometric tool of Pearson Product-Moment Correlation Coefficient is used for analysis. From the results in table-1, the Pearson Product-Moment Correlation Coefficient is -.913 , which shows a negative strong correlation among food security and rise in population growth.

Table 1: Relationship between Food Security and rise in Population Growth Correlations

\begin{tabular}{|l|c|c|c|}
\hline \multirow{3}{*}{ Food Security } & & Food Security & Rise in Population growth \\
\hline \multirow{3}{*}{ Rise in Population growth } & Pearson Correlation & 1 & $-.913^{* *}$ \\
\cline { 2 - 4 } & Sig. (2-tailed) & & .000 \\
\cline { 2 - 4 } & $\mathrm{N}$ & 300 & 300 \\
\cline { 2 - 4 } & Pearson Correlation & $-.913^{* *}$ & 1 \\
\cline { 2 - 4 } & Sig. (2-tailed) & .000 & 300 \\
\cline { 2 - 4 } & $\mathrm{N}$ & 300 & \\
\hline \multirow{2}{*}{$* *$ Correlation is significant at the 0.01 level (2-tailed). }
\end{tabular}

The figure-2 shows strong and negative association among Food Security and rise in Biofuel Production.

Figure 2: Relationship between Food Security \& Rise in Biofuel Production

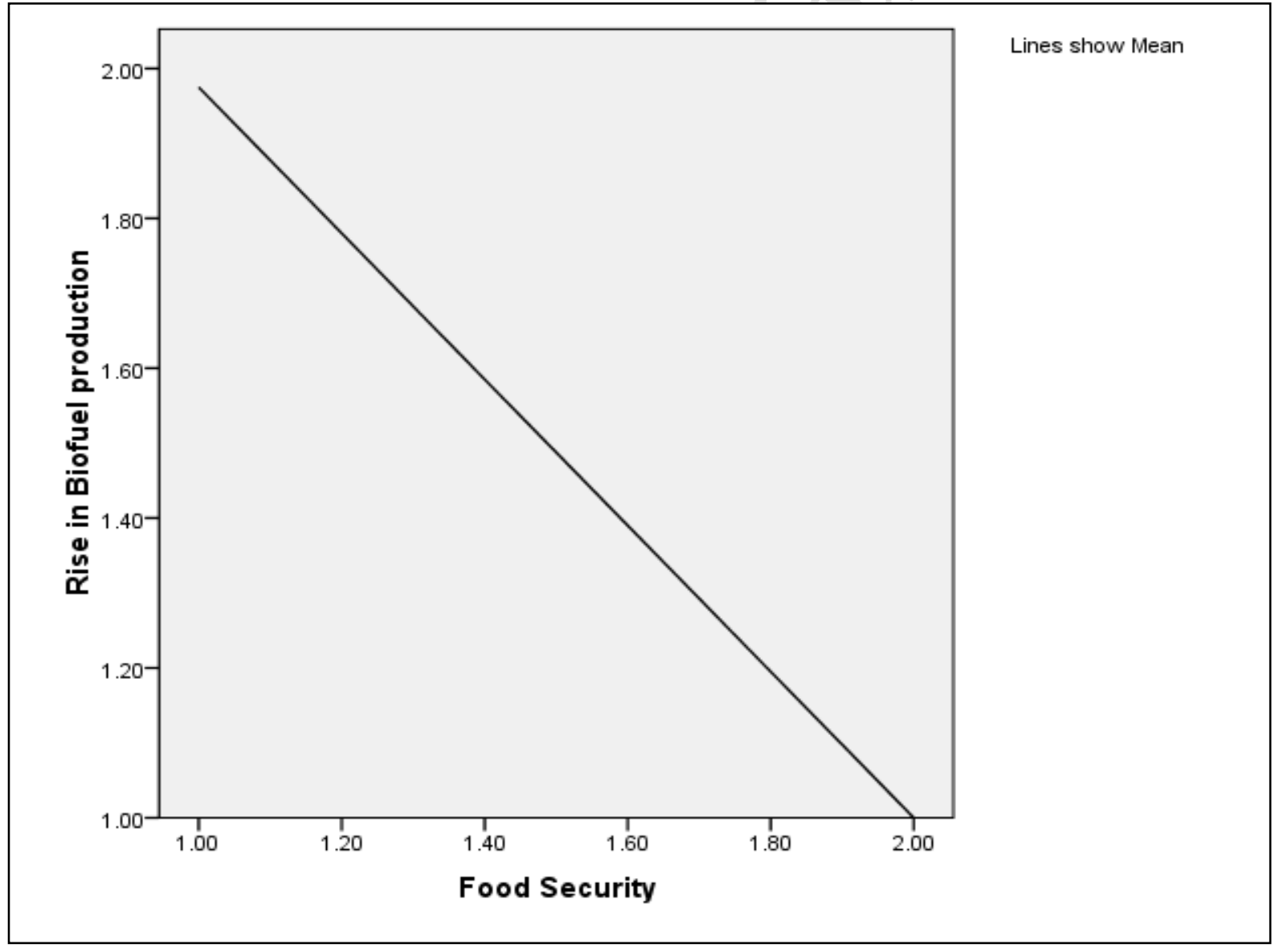

From the results of table-2, the Pearson Product-Moment Correlation Coefficient is -.844 , which shows a negative strong correlation among food security and rise in biofuel production. 
Table 2: Relationship between Food Security and rise in Biofuel Production Correlations

\begin{tabular}{|c|c|c|c|}
\hline \multirow{3}{*}{ Food Security } & & Food Security & $\begin{array}{c}\text { Rise in biofuels } \\
\text { production }\end{array}$ \\
\hline & Pearson Correlation & 1 & $-.844^{* *}$ \\
\cline { 2 - 4 } & Sig. (2-tailed) & & .000 \\
\cline { 2 - 4 } & $\mathrm{N}$ & 300 & 300 \\
\hline Rise in biofuels production & Pearson Correlation & $-.844^{* *}$ & 1 \\
\cline { 2 - 4 } & Sig. (2-tailed) & .000 & 300 \\
\cline { 2 - 4 } & $\mathrm{N}$ & 300 & \\
\hline \multirow{2}{*}{$* *$. Correlation is significant at the 0.01 level (2-tailed). } & \\
\hline
\end{tabular}

The figure-3 shows negative strong association among Food security and rise in Poverty.

Figure 3: Association among Food Security \& Rise in Poverty

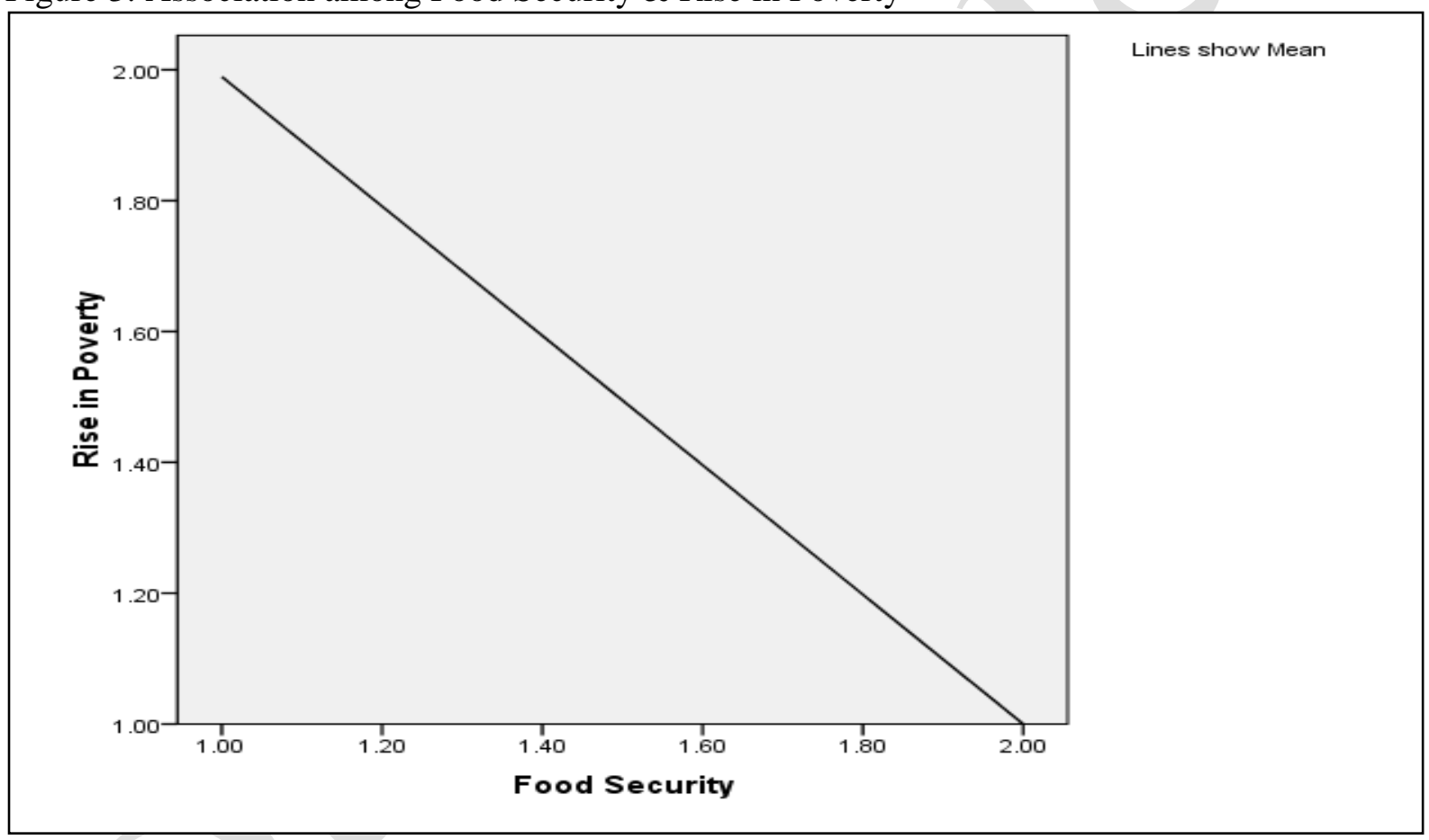

From the results of table-3, the Pearson Product-Moment Correlation Coefficient is -.924, which shows a negative strong correlation among food security and rise in poverty.

Table 3: Association among Food Security and rise in Poverty Correlations

\begin{tabular}{|l|c|c|c|}
\hline \multirow{4}{*}{ Food Security } & & Food Security & Rise in Poverty \\
\hline \multirow{3}{*}{ Rise in Poverty } & Pearson Correlation & 1 & $-.924^{* *}$ \\
\cline { 2 - 4 } & Sig. (2-tailed) & & .000 \\
\cline { 2 - 4 } & $\mathrm{N}$ & 300 & 300 \\
\hline & Pearson Correlation & $-.924^{* *}$ & 1 \\
\cline { 2 - 4 } & Sig. (2-tailed) & .000 & 300 \\
\cline { 2 - 4 } & $\mathrm{N}$ & 300 & \\
\hline \multirow{2}{*}{$* *$ Correlation is significant at the 0.01 level (2-tailed). } &
\end{tabular}


The figure-4 shows strong and negative relationship between Food Security and rise in the Social Unrest.

Figure 4: Relationship between Food Security \& Rise in Social Unrest

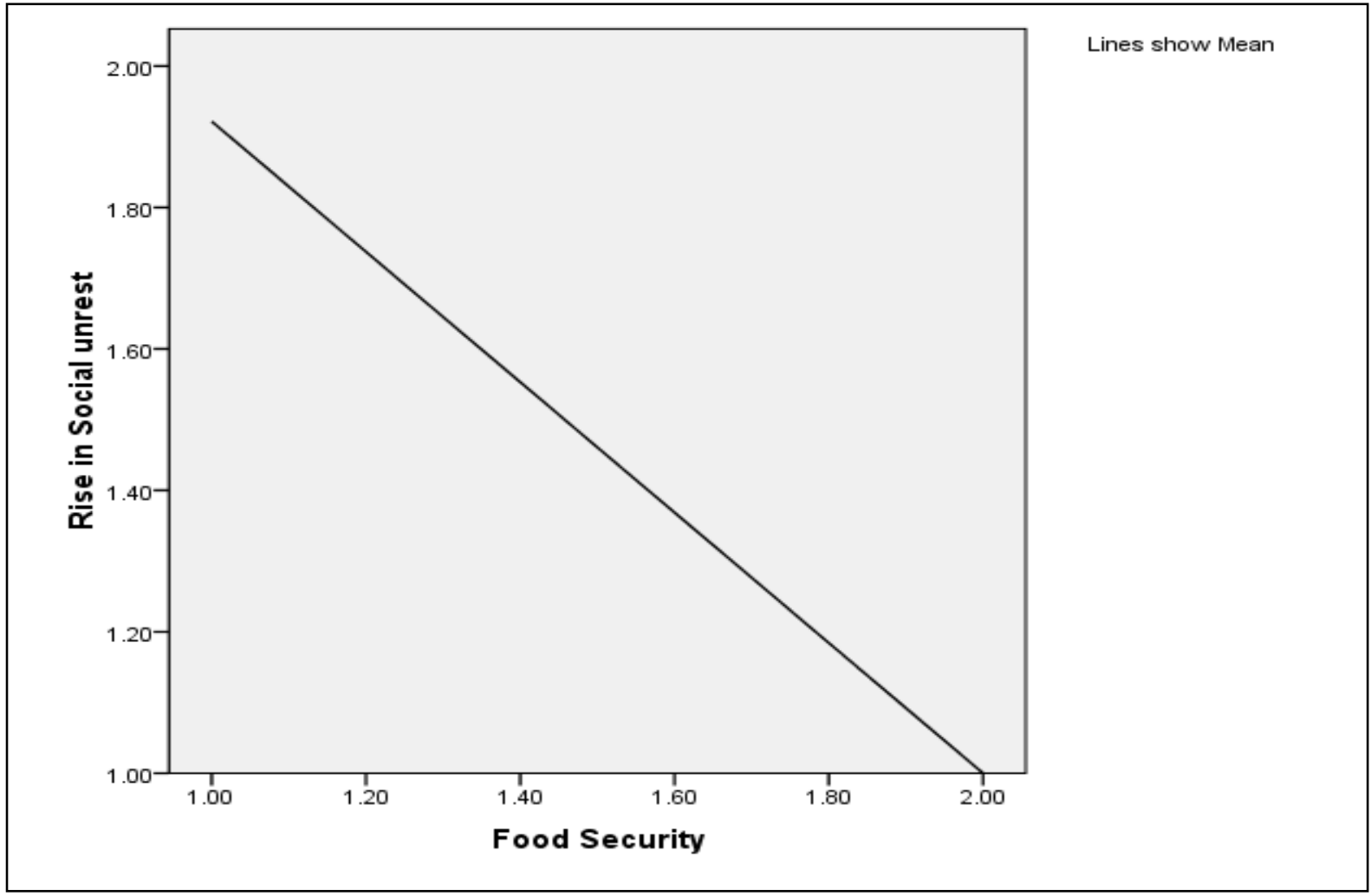

From the results of table-4, the Pearson Product-Moment Correlation Coefficient is -.654, shows a negative strong correlation among food security and rise in social unrest.

Table 4: Association among Food Security and rise in Social Unrest Correlations

\begin{tabular}{|l|c|c|c|}
\hline \multirow{4}{*}{ Food Security } & Food Security & $\begin{array}{c}\text { Rise in Social } \\
\text { unrest }\end{array}$ \\
\hline \multirow{4}{*}{ Rise in Social unrest } & Pearson Correlation & 1 & $-.654^{* *}$ \\
\cline { 2 - 4 } & Sig. (2-tailed) & & .000 \\
\cline { 2 - 4 } & $\mathrm{N}$ & 300 & 300 \\
\hline **. Correlation is significant at the 0.01 level (2-tailed). & Pearson Correlation & $-.654^{* *}$ & 1 \\
\cline { 2 - 4 } & Sig. (2-tailed) & .000 & 300 \\
\cline { 2 - 4 } & $\mathrm{N}$ & 300 & \\
\hline
\end{tabular}

\section{Discussion}

$\mathrm{KP}$ is facing "food insecurity" as an unavoidable and inescapable problem and this crisis must be overwhelmed and conquered as soon as possible. Poor people are suffering the most and are unable to buy basic food items due to high prices. This miserable situation has created harsh social unrest/stresses, containing poverty, malnourishment, hunger, rise in crime rates and destructive protesting etc. Food insecurity has led to political, social and economic instability 
in the KP. Protective measures must be taken on time. The following conclusions are made from the findings of the study.

There is strong and negative relationship between food security and rise in population growth. Thus, when there is active, prompt and quick rise in population growth, people face food insecurity. According to the 2017 census of Pakistan, the total population of Pakistan was $207,774,520$ against $132,352,279$ in the year 1998. Population growth rate is $2.1 \%$ and in the list of most populous countries, Pakistan is at 5th number. According to Population Census 2017, the total estimated population of KP was 30,523,371 and district Peshawar population was $4,269,079$. In many regions of Peshawar, there is simply not enough food to feed the growing population. Thus there is a need to control, regulate and check the massive, immense and extremely large population of Peshawar, so that food security can be enhanced and improved in Peshawar.

There is strong and negative relationship between food security and rise in biofuel production. Thus, when there is intense, forceful and quick rise in biofuel production, people face food insecurity. Rise in biofuel production has altered and crooked the food markets in three major means; firstly, it has distracted and used grains away and cut from food for fuel and gas along with corn now exercised, resorted and utilized to generate ethanol and almost half of vegetable oils moving in the direction of biofuel production. Secondly, farmers are encouraged, boosted and supported to locate and settle land specifically for the production of biofuel. Thirdly, biofuel production policies have provoked and boosted the food prices. Therefore, it is important that the erupting and sparkling influences of crop-based biofuels on food security and environment be acknowledged and recognized soon and examined thoroughly in the model of investment and developmental strategies and practices.

There is strong and negative relationship between food security and rise in poverty. Thus, when there is aggressive, excessive and quick rise in poverty, people face food insecurity. Poor people suffer a lot and are unable to buy basic food items due to high prices. Poverty is the main and chief hurdle and obstacle on the way of achieving better food availability, improved food access and greater food utilization. Poverty is the root cause of every problem in the society, has no doubts worse effects on human life. Traditional gender roles in Pakistan especially in KP, which remains indulged in tribal culture, define the woman's place as in the home and not in the workplace, and define the man as the breadwinner. Consequently, the society invests far less in women than men. Women in KP suffer more from poverty of opportunities throughout their lives as compared to other provinces. Eradication of poverty cannot be brought about by charity, but needs first and foremost empowering the poor, focusing on women, and tapping their tremendous potential. Poverty Eradication Initiative organizations and programmes must be launched to work as a facilitator to initiate and sustain women and children oriented developmental processes both at policy and community level on partnership basis. Such programmes must focus to support and improve quality of life of common citizens with the focus on the family and Society.

There is strong and negative relationship between food security and rise in social unrest. Thus, when there is sharp, vivacious and forceful food insecurity, people face rise in social unrest. Khyber Pakhtunkhwa is absolutely at risk of social unrest due to scarcity and inadequacy of food items and immense food prices. Crime rates, suicide rates and terrorism rates have been increased due to food insecurity. Thus, if prices of food items continue to remain high there is probably to be constant, determined and growing social unrest and disruption. There is a need 
for active, prompt, alert and circumstantial movement and operation to avoid and evade food insecurity and correlated social disruption.

\section{Conclusions}

Food insecurity is a primary and major issue in KP that must be solved and settled as soon as possible. The KP economy has already been invaded and assaulted because of severe food insecurity. It has accomplished the critical and crucial malnourishment and persistent hunger and famine. High food prices have generated extensive and prevailing destruction and chaos in the form of starvation, famine, social, political and economic instability and insecurity. Poor people are suffering the most and are unable to buy basic food items due to high prices. Due to hunger and famine, many people mostly poor are dying and this is extremely large dilemma and hindrance that has been enduring and undergoing for a long time and requisites to be settled and improved. The high food prices or food insecurity has forced and directed families into poverty, letting them with the adverse and destructive results of starvation and famine. The number of undernourished people is growing day by day due to high food prices. The malnourished, famine and hunger affected population is incapable to grant and devote to a strong, healthy and flourishing functioning and operating civilized authority for the KP's prosperity and comfort. Hence, there is a need to present and serve each and every feasible and attainable aim and measure to eradicate this crisis and guarantee that each and every individual is well-fed and nourished and provide economic strength to the KP. With the support of multiple organizations and NGOs, the condition is satisfied and allayed to some extent. Moreover, KP is affiliated with almost 50 International organizations such as UN, FAO, WHO, UNIDO and UNESCO which are helping and serving to alleviate and restore from poverty, hunger and famine and indeed to advance and flourish supportable industrial systems. However, yet food insecurity is an immense disturbance and stress that requires a lot of solutions and settlements.

\section{Recommendations}

For better and improved food security in KP, the following suggestions are recommended.

a) Effective measures are needed to control and reduce the growing rate of population. Large population is one of the main reasons behind food crisis. Demand for food is increasing day by day due to greater population, thus resulting in an inflation of food prices.

b) Government should demoralize the production of biofuels, such as ethanol, which uses up a heavy quantity of corn and bestows to increasing prices of food. It is suggested to advance and expand the biotechnology sector through which improve, better and enrich crops can be produced. Such crops are safe, immune to droughts and diseases and produce in larger quantity, thus increasing the food security for the people.

c) $\mathrm{KP}$ is facing high level of poverty which is the main obstacle in the way of attaining better food security. Poverty can be decreased if genuine and determined efforts are taken to achieve proper, equitable, fair and stable economic growth. Efforts to allow the poor to take part in the growth process and to provide them financial and market infrastructure. Efforts to invest in the health and education facilities of the poor.

d) Different projects about food security and agriculture must be taken into consideration; such projects will be helpful in strengthening the self-sustaining agricultural systems. Furthermore, efforts are required to help farmers to figure out how to improve their farming with latest technologies and to help in analysing their problems and troubles. 
There is a need of developmental institutions which operate with adequate awareness about self-sustaining agricultural structures and the social frameworks that support them.

e) For the complete eradication of food insecurity besides foreign aid the people of KP must also do efforts to become self-sufficient in terms of food security. They should properly and accurately utilize the modern agricultural technology given by developed Nations to its complete range and extent. Take serious steps to provide employment opportunities to the people in the worst, unfavourable and dreadfully affected regions of the KP.

f) KPK is facing poor political, social and economic conditions and thus is directly threatening food security. If immediate measures are not taken to improve the political, social and economic conditions, it would result in pushing the food-insecure people into militants and consequently generate the new generations of extremists.

\section{References}

Abbas, G., Ahmad, S., Ahmad, A., Nasim, W., Fatima, Z., Hussain, S. \& Boote, K. J. (2017). Quantification the impacts of climate change and crop management on phenology of maize-based cropping system in Punjab, Pakistan. Agricultural and Forest Meteorology, 247, 42-55. https://www.sciencedirect.com/science/article/pii/S0168192317302289

Abid, M., Schilling, J., Scheffran, J., \& Zulfiqar, F. (2016). Climate change vulnerability, adaptation and risk perceptions at farm level in Punjab, Pakistan. Science of the Total Environment, 547, 447-460. https://www.sciencedirect.com/science/article/pii/S0048969715311086

Arshad, S., \& Shafqat, A. (2012). Food security indicators, distribution and techniques for agriculture sustainability in Pakistan. International Journal of Applied Science and Technology, 2(5). https://www.academia.edu/download/37312118/Food_security_indicators.pdf

Arif, M., \& Khalid, N. (2007). Agriculture and food security in Pakistan. South Asia Partnership Pakistan. http://www.sappk.org/wpcontent/uploads/publications/eng_publications/Agriculture and_Food_Security.pdf

Ahmad, M., \& Farooq, U. (2010). The state of food security in Pakistan: Future challenges and coping strategies. The Pakistan Development Review, 49(4), 903-923. https://www.jstor.org/stable/41428696

Ahmad, D., Afzal, M., \& Rauf, A. (2019). Analysis of wheat farmers' risk perceptions and attitudes: evidence from Punjab, Pakistan. Natural Hazards, 95(3), 845-861. https://idp.springer.com/authorize/casa?redirect_uri=https://link.springer.com/article /10.1007/s11069-018-3523-

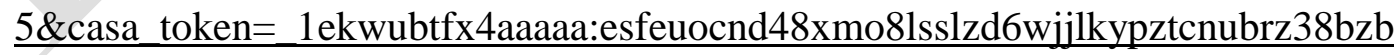
mqvzfsfl7igo5lhdpo3kgcprl12i9rysk2-hbq

Ahmad, D., \& Afzal, M. (2020). Flood hazards, human displacement and food insecurity in rural riverine areas of Punjab, Pakistan: policy implications. Environmental Science and Pollution Research, 1-15. https://idp.springer.com/authorize/casa?redirect_uri=https://link.springer.com/article /10.1007/s11356-020-11430-

7\&casa_token=3pgj59tj4hgaaaaa:xp4mg0a1fq4qjb8rmk5n28lyg6ahl4wnxbalippto9 wkkotmfs8iokptxba0t8u-ohlyzosad22x8etb 
Ahmad, D., \& Afzal, M. (2020). Flood hazards and factors influencing household flood perception and mitigation strategies in Pakistan. Environmental Science and Pollution Research, 27: 15375-15387, 1-13. https://doi.org/10.1007/s11356-02008057-z

Alam, G. M., Alam, K., Mushtaq, S., Sarker, M. N. I., \& Hossain, M. (2020). Hazards, food insecurity and human displacement in rural riverine Bangladesh: Implications for policy. International Journal of Disaster Risk Reduction, 43, 101364. https://www.sciencedirect.com/science/article/pii/S2212420918309361

Altaf, Z. (2009). Food security in pluralistic Pakistan. HUNGER. https://citeseerx.ist.psu.edu/viewdoc/download?doi=10.1.1.689.5552\&rep=rep1\&ty pe $=$ pdf\#page $=39$

Bengali, K., \& Jury, A. (2010). Hunger Vulnerability and Food Assistance in Pakistan: The World Food Program Experience. HUNGER. http://citeseerx.ist.psu.edu/viewdoc/download?doi=10.1.1.689.5552\&rep=rep1\&typ $\mathrm{e}=$ pdf\#page $=124$

Farrukh, M. U., Bashir, M. K., \& Rola-Rubzen, F. (2020). Exploring the sustainable food security approach in relation to agricultural and multi-sectoral interventions: A review of cross-disciplinary perspectives. Geoforum, 108, 23-27. https://doi.org/10.1016/j.geoforum.2019.11.012

Gulab, S., Fazli, R., \& Umar, H. (2018). Food insecurity and its determinants in rural Khyber Pakhtunkhwa, Pakistan. Asian Journal of Agriculture and Biology, 6(3), 308-315. https://www.cabdirect.org/cabdirect/abstract/20193272893

Kugelman, M. (2010). Pakistan's Food Insecurity: Roots, Ramifications, and Responses. HUNGER.

http://citeseerx.ist.psu.edu/viewdoc/download?doi=10.1.1.689.5552\&rep=rep1\&typ $\mathrm{e}=$ pdf \#page $=13$

Malik, S. J., Nazli, H., \& Whitney, E. (2015). Food consumption patterns and implications for poverty reduction in Pakistan. The Pakistan Development Review, 54(4), 651-669. https://www.jstor.org/stable/43831350

Nyarko, A. D., \& Kassai, Z. (2017). High rice import as a threat to food security and a hindrance to sustainable rice production in Ghana. Archives of Current Research International, 1-13. http://www.journalacri.com/index.php/ACRI/article/view/18171

Př́vara, A., \& Přívarová, M. (2019). Nexus between Climate Change, Displacement and Conflict: $\quad$ Afghanistan $\quad$ Case. Sustainability, 11(20), 5586. https://www.mdpi.com/2071-1050/11/20/5586

Toor, S. (2010). The structural dimensions of food insecurity in Pakistan. HUNGER. http://www.academia.edu/download/5947070/pakistans_food_insecurity.pdf\#page= $\underline{107}$

Week, D. A., \& Wizor, C. H. (2020). Effects of flood on food security, livelihood and socioeconomic characteristics in the flood-prone areas of the core Niger Delta, Nigeria. Asian Journal of Geographical Research, 1-17. http://www.journalajgr.com/index.php/AJGR/article/view/30096

Zhou, D., Shah, T., Ali, S., Ahmad, W., Din, I. U., \& Ilyas, A. (2019). Factors affecting household food security in rural northern hinterland of Pakistan. Journal of the Saudi Society of Agricultural Sciences, 18(2), 201-210. https://www.sciencedirect.com/science/article/pii/S1658077X16301709 